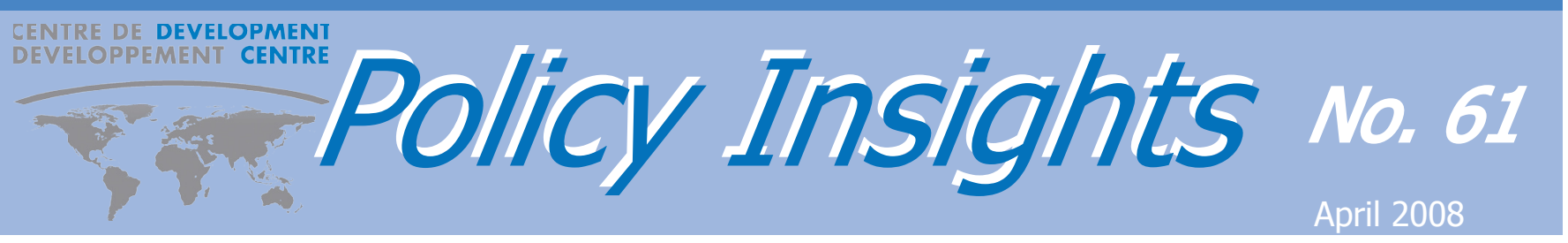

\title{
Evaluating the Effects of Vocational Training in Africa
}

\section{(based on the African Economic Outlook 2008*)}

\author{
by Christian Kingombe
}

- More and better data are needed to monitor and evaluate the impact of vocational training on economic growth and poverty reduction.

- Labour market observatories can help align training systems to labour market needs.

- Analysis of youth unemployment is essential before investing in expensive training schemes.

The impact of vocational training on economic growth and poverty reduction in African countries is unknown. Without such knowledge, however, countries and donors cannot formulate appropriate policies. Even the 35 countries surveyed in the 2008 African Economic Outlook can only supply approximate data ${ }^{1}$.

Technical and Vocational Skills Development in Africa occurs at different levels of education. Governments and donors need to produce the mix of skills that best corresponds to the requirements of countries at their specific stage of economic development. In addition, skills and vocational training policies are most effective when they are in line with overall development policies and the needs of the labour market.

Hence, the need to produce cogent analyses of the contribution of vocational training to a country's developmental process has become paramount. Not only does it permit governments and NGOs to select programmes that contribute most to overall personal and national development, but it provides a means whereby other stakeholders, particularly donors, can see the value of their contributions. The best analysis of vocational training programmes and policies draws on past experience and assesses the impact on beneficiaries' lives and careers. The impact of training can thus be assessed, taking into account the general environment, which will include natural resources, the business environment, the availability of equipment, demand and access to markets. Taking into account all these elements should improve service delivery, planning and resource allocation.

1.The African Economic Outlook is published annually by the African Development Bank and the OECD Development Centre.
Analysis of training programmes in the informal sector of Côte d'Ivoire during 1994-2002 indicated which ones produced positive economic impacts; in Benin a study of programme quality over 2000-2005 showed possible positive outcomes, since 60 per cent of participants said that their turnover and profits had increased while costs had fallen.

The value of training, then, is not in doubt.

The maximum employability of the labour force through better skills acquisition, however, depends not only on the quality the skills themselves, but also on the dynamism of the economic environment in which they can be applied and the supply of training available. Governments can better monitor the quality of private training provision through encouraging private institutions alongside government-funded facilities. This has been shown to work in Zambia, for example.

Monitoring and evaluation mechanisms of vocational and training programmes are still too rare in Africa. This leads to a paucity of data on youth unemployment, lack of assessment of projects, poor or non-existent evaluations of past programmes, and a critical shortage of impact studies. The creation of vocational training and labour market observatories in many African countries can help tackle these shortcomings. Such observatories can support the efficient use of training funds and identify appropriate beneficiaries whose personal and professional needs can be aligned with those of the labour market. Their method of working is relatively simple: collating statistics on changes in the labour market and conducting surveys within both the labour force and potential employers. 
They are thus well within the means of most African countries and their contribution to national, regional and local planning could be considerable.

Their value has been demonstrated by the African Development Bank and the OECD Development Centre in their African Economic Outlook. The AEO shows that five years after graduation, about a quarter of the Namibian former Vocational Training Centres students regard themselves as unemployed; in Zambia, on the other hand, a 2004 study showed that most similar graduates found a job after six months.

Investigating the core causes of youth unemployment is an essential first step to make training relevant for the labour market before costly investments are made. This simple observation is too often ignored.
Two other 2006 studies reported in the African Economic Outlook show that only just over half the 25 Rwandan enterprises interviewed were satisfied by the training graduates' performance. The Botswana Training Authority (BOTA) discovered though a 2005 study that the country's training institutes do not produce readily employable people mainly because of the absence of practical experience in the training programmes. There are similar doubts in Namibia. There are indications that this type of mismatch is present in most African countries.

This evidence reinforces the argument for graduatetracking studies, regular labour market skills surveys, and future skills-needs projections. This active labour market approach will enable governments to be better placed to deliver manpower development plans, training curriculum design and appropriate facilities through the private and public sectors.

* published jointly by the African Development Bank and the OECD Development Centre with the United Nations Economic Commission for Africa with financial support from the European Commission.

Readers are encouraged to quote or reproduce material from $\mathrm{OECD}$ Development Centre Policy Insights for their own publications. In return, the Development Centre requests due acknowledgement and a copy of the publication. Full text of Policy Insights and more information on the Centre and its work are available on its web site: www.oecd.org/dev

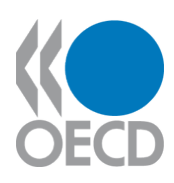

OECD Development Centre 2 , rue André-Pascal, 75775 Paris Cedex 16, France Tel.: +33-(0)1 45.24.82.00

Fax: +33-(0)144306149 E-mail: dev.contact@oecd.org 